The Arbutus Review • $2018 \bullet$ Vol. 9, No. 1 • https://doi.org/10.18357/tar91201818385

\title{
Women in Weed: Gender, Race, and Class in the Cannabis Industry
}

\author{
Jacqueline Kittel ${ }^{*}$ \\ University of Victoria \\ jackittel@gmail.com
}

\begin{abstract}
The legitimate cannabis industry is in its developmental stages across North America, leading some to claim that this industry will be a "blue skies market for women" where they will have unfettered opportunities to take on influential and entrepreneurial roles. This discourse, however, ignores the reality that the cannabis industry is just as shaped by gender and intersectional inequalities as other more established industries. Drawing on interviews with five women leaders from various cannabis sectors in Vancouver and Victoria, British Columbia, I explore how gender, racialization, and class operate in this increasingly corporatized sector and how white, heteronormative femininity has been used to normalize cannabis consumption
\end{abstract}

Keywords: cannabis; gender; race; corporatization; legitimization

$\mathrm{T}$ he cannabis industry in Canada is on the cusp of massive changes - from a highly stigmatized and criminalized underground market to a world of gleaming factories owned and operated by powerful corporations as federal legalization fast approaches. This development from the illicit to everyday use has occurred in a very short period and women have been central players in this shift in attitudes. Based on five in-person interviews with women leaders from various cannabis sectors in Vancouver and Victoria, British Columbia, this paper explores how gender, racialization, and class are being employed by participants in the cannabis industry. This paper further analyzes what role these identities play in legitimizing and normalizing cannabis consumption. It also interrogates a common discourse in the cannabis community and the popular media, which suggests that, as a new and burgeoning sector, the cannabis industry is a "blue skies market for women" (Kind, 2015) namely that women have an unfettered opportunity to take on influential and entrepreneurial roles.

\section{Literature Review}

In Canada at the time of this study, cannabis is regulated as a Schedule II drug under the Controlled Drug and Substances Act (Health Canada, 2016). Schedule II drugs are substances that the federal government has categorized as having a higher than usual potential for abuse or addiction. Surprisingly, Canada was the first nation in the world to outlaw cannabis consumption in 1923, 14 years before the United States (Schwartz, 2014). Beginning in the 1970s, the prohibition of cannabis was amplified in Canada and the US as part of the global "War on Drugs," the argument being that the latter was necessary to combat gang activity and youth consumption through strict punishment and control (Gordon, 2006). Fast-forward 94 years and cannabis remains in a grey zone in regards to federal legalization in Canada, but that has not stopped the cannabis industry from

\footnotetext{
*I would like to thank Dr. Annalee Lepp for her support as my supervisor and the Jamie Cassels Undergraduate Research Awards for providing financial aid in this research project.
} 
thriving in the illegal and legal realms. Canada is currently developing regulations for a federally legal recreational cannabis market that is set to be introduced in the Fall of 2018. The Cannabis Act, or Bill C-45, received Royal Assent on June 19th, 2018 and is expected to be legal across Canada as of October 17th, 2018 (Scotti, 2018). At present, the cannabis industry is comprised of federally legal Licensed Producers (LPs) who are authorized by Health Canada; federally illegal compassion clubs and storefront dispensaries that are being regulated on municipal levels; and the underground illicit market that has been thriving under prohibition for the past several decades. My research participants currently operate in the illegal cannabis industry, meaning prohibition has been one of the most significant factors in shaping their experiences in the industry.

Although there is existing academic literature that considers the various economic and health impacts of cannabis, there is little peer reviewed literature that examines women's roles in the industry or academic studies that apply a critical feminist and/or intersectional lens to the topic. This research project is significant because it seeks to address the current gap in the existing body of knowledge on this topic. In spite of a lack of research, I did uncover information online about a US-based professional networking organization based out of Denver, Colorado known as Women Grow. Women Grow currently hosts 45 local chapters across the United States with a chapter in Eastern Canada. Monthly chapter meetings and an annual conference work to create a woman-friendly environment designed to foster the development of women's relationships with other women industry members. Jamie Shaw, one of my participants, was a co-founder of the Vancouver chapter of Women Grow.

In a 2015 online interview with Matthew Kind for Canna Insider, Jazmin Hupp, co-founder of Women Grow, described the current state of the cannabis industry and women's role in it as follows:

The marijuana industry is blue ocean right now, blue sky. There's no reason for us to even treat each other like competition because the market is going be large enough that there is room for everyone right now. (Kind, 2015)

Even though Women Grow was established to address gender inequities in the cannabis industry, the discourse proposed by its co-founder suggests that the industry is simply awaiting confident women willing to make their mark in this quickly growing industry. This perception of women's access does not adequately acknowledge gender based discrimination and systemic economic inequalities that impact women's experiences. Susan Boyd (2015), author of From Witches to Crack Moms, argues the contrary and provides historical and sociological evidence that the global war on drugs has disproportionately impacted women for the worse, especially women from racialized or impoverished backgrounds (p. xi).

The above claims from Jasmine Hupp do not adequately grapple with or acknowledge the invisible obstacles women must overcome to fully participate and succeed in the cannabis industry. There are gendered and racialized differences in regards to risk, financial capacity, and domestic responsibility that influence women's access, which are largely ignored in the blue skies market discourse. For example, Boyd (2015) argues that women face more significant social repercussions for consuming illicit drugs as compared to men due to associations of femininity with the sanctity of the home, mothering, sobriety, and morality that constrain women to behave "appropriately" or face major repercussions (p. xiii). I hypothesize that the description of a blue skies cannabis industry is misleading and that the industry as it stands is not outside of hierarchical gender logics, binaries, and racialized perceptions that influence women's access. In fact, Ashley Abraham (2016), founder of The Green Ceiling, addressed this issue in our interview; she distinguished between what we want the industry to be versus what it is and pointed out that the cannabis industry is "a brand new legitimate industry but it's not a brand new industry." The cannabis industry has a history and that history is gendered. 
In addition to unnamed gender based inequalities, when an intersectional lens is applied to the industry, several issues emerge. Wanda James is the owner of Simply Pure and the first woman of colour to own a medical dispensary in Denver, Colorado. In an interview with Ricardo Baca from The Cannabist (2015), James critiqued the equal opportunity image of the cannabis industry and names the ways in which people of colour are differently situated in the industry as compared to white citizens. James argued that racialized populations are structurally and disproportionately criminalized across North America, which was made worse by the "War on Drugs" that has been ravaging communities of colour for decades, which has an impact on the relationship between these communities and the legal market. James has also pointed out that, though there are more women leaders in the cannabis industry as compared to other industries, women continue to represent a minority of the leaders in the cannabis sector.

Dell and Kilty's (2013) research on Aboriginal women drug users in Canada describes the influence of race, gender and class that contribute to the stereotype of the "expected offender" image imposed upon Aboriginal women. Dell and Kilty's work demonstrates the role of colonization and ongoing marginalization that perpetuates a societal distrust of Aboriginal female drug users. A powerful stereotype constructs this demographic of women as deserving of punishment and criminalization for the cultural perception of self-induced drug use and the correlating harms associated with that use (p. 53). The stigmatization of Aboriginal female drug users in Canada is reflected in the reality that, "in comparison to non-Aboriginal women, Aboriginal women are disproportionately policed, charged, convicted, and sentenced to time in prison for their drug use" (Dell \& Kilty, 2013, p. 53). Race, as with gender and class, makes a significant difference in regards to how women may access, interact with and succeed in the cannabis industry due to historical, cultural, and social factors that differently situate women in the public realm.

To claim that the cannabis industry is an open and "blue skies" market for women is to ignore the many and overlapping systemic and ideological barriers that insidiously define who is able to sit at the cannabis industry's negotiation table and whose voices are really heard when it comes to determining the future of the industry.

\section{Methodology}

To assess the gendered and intersectional dimensions of the cannabis industry, I employed a qualitative research approach and conducted audio recorded in person interviews with five women leaders and activists with long careers in various cannabis businesses in Vancouver and Victoria. My participants included Jamie Shaw, the past president of the Canadian Association of Medical Cannabis Dispensaries and past director of the BC Compassion Club Society; Sarah Campbell, co-founder and director of The Craft Cannabis Association of BC; Brandi Woods, past general manager of the Victoria Cannabis Buyers Club; Mary Jean Dunsdon (a.k.a. Watermelon), an online media personality, baker, and cannabis activist; and Ashley Abraham, founder and director of The Green Ceiling Vapour Lounge. I asked each participant six questions that prompted them to critically engage with various issues related to the cannabis industry. These questions included the ways in which their gender identity had either enhanced or inhibited their ability to become leaders, the question of diversity in industry members, and their visions for women's participation moving into the future. My recruitment strategy relied upon networking with my personal friend and mentor Ted Smith, who has been a local cannabis activist fighting for cannabis legalization in Victoria for the past 22 years. Ted consented to assist me as a resource for contacting potential research participants for my study due to his extensive career and involvement in the industry and the professional relationships he has developed in that time. Working with an industry insider was a strategic option to push my research project outside of the traditional limits of a student 
project. Ted was the primary contact with my participants and once participants had contacted me and agreed to assist me with my project, I forwarded Participant Consent Forms to obtain fully informed consent to publish their names and stories in this work. The narrow scope and time available in which to conduct my research resulted in the ability to interview a maximum of five women. Therefore, I made the decision to reach out to women working in a range of sectors with the goal of providing a cross sectional assessment of the ways in which gender is being employed in many different areas of the industry.

Prior to conducting in person interviews with these industry insiders, I obtained approval from the University of Victoria's Human Research Ethics Board to proceed with my research and data collection. The application required assessing and mitigating all potential harms and taking into account all ethical considerations related to the research project. In addition to tangible ethical concerns in the research process, I am faced with conceptual ethical concerns including the risk of theoretically homogenizing the cannabis industry and women's experiences in my writings. The cannabis industry greatly varies from one community to the next; therefore, the central political motivators for women leaders working in one community may be significantly different from the political concerns and motivations of women leaders in different communities. Similarly, as DeVault and Gross' (2006) writings explain, researchers must work in accordance with the widely held feminist stance that "woman" cannot be theorized as a unified and foundational subject, meaning that any conclusions I draw cannot be applied broadly to all women in the industry (p. 175). Therefore, my research findings will be limited on several fronts: by the number of women able to participate in my study, that the experiences of my participants do not necessarily apply to all women's experiences in the industry, as well as being limited to the regional context of the Lower Mainland of British Columbia and the south coast of Vancouver Island.

To conduct my research ethically and to ensure that I did not misrepresent my participants, I chose to adopt a feminist research methodology that is "reflexive and relational" (DeVault \& Gross, 2006 , p. 175) and that would allow me to interrogate my own biases and "situated perspectives" (Lal, 1996, p. 188). Doing so involved critically engaging with my own assumptions, limited perspectives, and personal agendas in regards to the research outcome.

The theoretical tools I employed to analyze my primary research were based in a feminist and intersectional theoretical framework. As discussed above, I adopted the suggestions of DeVault and Gross (2006) and applied a feminist research methodology that requires researchers to be aware of the dynamics of power in the research context, to be cognizant of the politics of representation involved in representing a person's experiences, as well as the material and social consequences of knowledge production and claims to truth. I have also applied an intersectional analysis grounded in Kimberlé Crenshaw's work that calls attention to the significance of intersecting identities and power that differently affect women's experiences (Crenshaw, 1991; Dawson \& Henley, 2015). No woman in the cannabis industry, or society more broadly, is defined by one component of their identity and if theorizations of the gendered dimensions of the cannabis industry are to be relevant and applicable to the lived experiences of women, research must address questions of intersecting identities. Due to the limited scope of this research project, this paper primarily focuses on the intersections of race, class, and gender. Further research is required to more fully develop a critical analysis of the significance of intersecting identities in the cannabis industry.

\section{Findings}

Based upon the interviews I conducted with these professional and well-qualified industry leaders, I uncovered several recurring themes that emerged throughout the transcription process concerning the role of gender and femininity in the cannabis industry. The remainder of this paper is organized 
thematically based upon the recurring themes and issues my participants discussed. These themes are rounded out with theoretical accounts of the motivating factors and social systems that inform the social phenomena my participants discussed so as to develop a critical gender and intersectional analysis of the cannabis industry in Southern British Columbia in 2017/2018. These themes include discussions about the corporatization of the cannabis industry and the correlating racialization of industry involvement; the gendered contours of the industry; and how gender essentialism has been used as a strategy to legitimize the industry.

\section{Corporate Culture and the Racialization of the Cannabis Industry}

\section{Racialization}

Racialization refers to the process wherein specific characteristics are imposed upon communities based upon historically situated social constructions of difference (Pila, 2014). Race functions as a method of establishing signifiers of difference based upon perceived innate characteristics and then allocating resources and rights to privileged racial groups at the expense of communities deemed "other" by those in power. In Canada, centuries of colonialism have created a white settler nation wherein whiteness is taken as a "natural" or invisible mode of being that is privileged over communities of colour, who continue to face discrimination and oppression based on racial categorization. The cannabis industry, as young as it may be, is not exempt from racial politics, just as it is not outside of gender or class politics.

The racial politics of the cannabis industry has largely been shaped by federal prohibition and criminalization. Decades of government propaganda developed a dominant understanding of cannabis as a harmful substance, a blight on society and as an industry dominated by gangs and criminals. Criminalizing cannabis from the outset was a method of tying an undesirable product to undesirable populations in the eyes of those in power and had little to do with meaningful public welfare concerns. Steven Bender (2016), the author of The Colors of Cannabis: Race and Marijuana, writes that from the very beginning, "marijuana criminalization, as with cocaine and opiates, stemmed from racialized perceptions of users of color as threatening public safety and welfare" (p. 690).

To provide a historical understanding of the role of race in the cannabis industry, we must look to the writings of politicians and social influencers at the turn of the 20th century. To justify the prohibition of cannabis in North America, prohibitionists succeeded in discursively associating cannabis use with "unproductive" (i.e., racialized) members of society. For example, the writings of Emily Murphy - a first wave feminist activist, writer and jurist - contributed greatly to the cultural hysteria towards drug use in Canada. In 1916, Murphy was appointed as the Police Magistrate and Judge of the Juvenile Court in Edmonton, Alberta. Throughout her time in the public eye, Murphy penned many articles under the name "Janey Canuck" for MacLean's Magazine that were later compiled into a book titled, The Black Candle (1973). The Black Candle propagated a distinctly anti-Chinese sentiment that reinforced a sensationalist and racialized fear of non-white drug users. The Black Candle depicts many alarming and disturbing images of drug users that are supported by the "expert" testimony of those working in the helping profession of the era. Ultimately, her work portrays drugs and drug users as a menace and threat to civil society brought on primarily by Chinese and black communities in Vancouver, BC. Murphy's writings were situated in a moment in Canadian history that is defined by white supremacy and which formed the foundation for the racialized war on drugs we continue to live with today.

In addition to the racialized image of the cannabis community, a classed and gendered representation of cannabis users continues to circulate in the current era that can be best described as the "Stoner Bro" stereotype. Watermelon described this stereotype as "a Rastafarian guy or it's Cheech 
and Chong, it's usually somebody like, 'whoa dude,' who like you know doesn't have that great of a vocab 'man,' you know what I mean, they just want to surf." The power of the prevalent Stoner Bro stereotype worked in modern prohibitionists' favour to discursively produce a stereotyped image of cannabis users as men in general, and of racialized men as criminals in particular.

\section{Corporatization}

Over the years, cannabis activism has challenged prohibition, the Stoner Bro stereotype, and the association with racialized gang culture by emphasizing the medicinal uses of cannabis (McLaren, 2018). The amazing work of pioneers such as Hilary Black, who opened one of Canada's first medical cannabis dispensaries in 1997, set the stage for the development of the cannabis industry as we know it today. Activists Michelle Rainey, one of Canada's most influential patient advocates and Libby Davies, a powerful elected voice in the Canadian Parliament in the early 2000s, had significant influence on the modern cannabis industry in Vancouver, BC. Rielle Capler, Rosy Mondin, Lisa Campbell, Bethany Rae, Alison McMahon, Alison Gordon, Melissa Rolston and countless others have given immeasurable hours of work and dedication to move cannabis out of the shadows and into the homes of Canadians. The work of these women and countless others have paved the way through federal prohibition and taken significant risks to allow myself and others the opportunity to work in this thriving industry.

The work of these activists set the stage for a major cultural shift in the perception of cannabis. The exponential number of storefront cannabis retailers lining city streets across Canada has been the result of a move away from the stereotyped image of cannabis users as cannabis consumption moves into the mainstream. Ultimately, the shift in the dominant perception of cannabis businesses has provided a ripe opportunity for wealthy white business corporate culture to reap the benefits of impending legalization within this retail context. In other words, this is the process whereby the cannabis industry is being corporatized.

The Access to Cannabis for Medical Purposes Regulations (ACMPR), which was implemented in August 2016, is Canada's most recent set of regulations that oversees the legal cannabis industry. Though soon to be replaced by The Cannabis Act, the ACMPR is the current legal model that "sets out a framework for commercial production by licensed producers responsible for the production and distribution of quality-controlled fresh or dried marijuana [...] in secure and sanitary conditions" (Health Canada, 2016). At the time of writing, Canada's current and proposed regulations prioritize Licensed Producers (LPs) as legal manufacturers of cannabis for medical and recreational marijuana users outside of home production. LPs are large-scale corporations that are heavily regulated, have a staggeringly high cost for entry, and must meet exceptionally strict compliance, security codes, and health standards. Jamie Shaw argued in our interview that the federal government's preference for this model of mass produced agri-business seeks to make the barriers to entry exceptionally high, to the detriment of craft cannabis growers or new industry entrants. While imposing high security and sanitation standards is not unreasonable, the proposed regulations require expensive equipment and high regulatory regimes in order to receive a license. LPs are massive operations that are in the business of mass production and for profit corporate culture. Canada's response to regulating the industry has been to re-invest in male dominated, white washed corporate culture.

With this image of a corporatized cannabis industry in mind, it is important to ask what role systematic gender barriers play in impacting women's ability to access the necessary capital required to meet Health Canada's regulations to participate in the legal industry. First of all, men have historically and continue to make up the bulk of cannabis industry participants. Jamie Shaw expressed that, prior to the establishment of Women Grow, it was quite common for speaker panels at cannabis conferences to be an uninterrupted lineup of male voices. Even amongst grass 
roots cannabis activist organizations, sexism remains alive and well. Sarah Campbell, one of the co-founders of the Craft Cannabis Association recounted that more than once the men at the table of cannabis business meetings expected her to take the minutes because she was a woman. Moreover, large-scale business enterprises in Canada are not exempt from gender inequality in the diversity and representation of women in leadership and executive roles across multiple sectors; therefore, why would we expect the cannabis industry to be that different? The Osler Corporate Practice Group analyzed the gender diversity of companies listed on the TSX and of the 750 companies that reported on the gender makeup of their board of directors, women represented a minority with $12.6 \%$ of total board seats (MacDougall et al., 2017, p. 10).

The Canadian federal government is most comfortable with handing the reins of the industry over to "legitimate" business enterprises that most resemble corporations, which is a role that Licensed Producers fulfill. Whiteness is integral to this process of corporatization as it functions to sanitize the cannabis industry's assumed racialized roots. By aligning the legitimate cannabis industry with white male business culture, the industry becomes more accessible and appealing to white middle-class consumers who are uncomfortable with the association of cannabis and street dealing. This process was also evident in two storefront retail dispensaries I have worked in that had rules against playing music from black culture such as rap or Rastafarian music due to its association with the Stoner Bro stereotype. My participants shared similar anecdotes and agreed that the cannabis dispensaries in Victoria and Vancouver are overwhelmingly white dominated. By removing the associations of blackness, the underground, and the Stoner Bro stereotype, modern retail cannabis stores are drawing on the legitimizing power of whiteness and corporate environments to sell their products to mainstream consumers.

Identifying the role of race and racialization in this process of corporatization is important because whiteness holds most of its power when it is invisible and unnamed (Frankenberg, 1993, p. 1). To name whiteness and its power is to identify who is being given the authority to dominate the industry and who is left on the outside with little voice or representation. Discussing the racial composition of the cannabis industry additionally exposes the structural inequalities that position people differently in their ability to succeed in the legal industry. This evidence contradicts the "blue skies" depiction discussed above by demonstrating how the industry is becoming white dominated as corporatization takes over. Michelle Alexander, the author of The New Jim Crow: Mass Incarceration in the Age of Colorblindness, points out the crushing irony of this shift when she explains:

Here are white men poised to run big marijuana businesses, dreaming of cashing in big big money, big businesses selling weed - after 40 years of impoverished black kids getting prison time for selling weed, and their families and futures destroyed. Now, white men are planning to get rich doing precisely the same thing? (Alexander, 2012, as cited in Bender, 2016, p. 695)

\section{Gendered Dimensions of the Cannabis Industry}

As we have seen, the cannabis industry is not outside of larger systems of power that differentiate people's ability to participate in an increasingly corporatized cannabis industry based on the social locations of race and class. My interview participants also discussed in detail how gender plays a significant role in shaping the industry. 
The Arbutus Review • $2018 \bullet$ Vol. 9, No. $1 \bullet$ https://doi.org/10.18357/tar91201818385

\section{Boobs and Bongs}

A common issue my participants raised was the prevalence of sexualized representations of women in the cannabis community that has dominated cannabis media for the past 20 years. In fact, images of hypersexualized young women photographed in lingerie with bongs and clouds of smoke were the main portrayals of women the cannabis community distributed. Women were used largely as sexual objects to sell cannabis products to Stoner Bros, the target market of the industry throughout the 1990s and 2000s. Women industry leaders I interviewed held differing perspectives on whether such sexualized representations are a source of empowerment or an expression of gender inequality and sexism.

Watermelon, a popular cannabis activist and media personality, challenged the assumption that sexualized representations of women are detrimental. During our interview, she explained that she had been a centerfold calendar girl for High Times magazine three times throughout her career. Watermelon suggested that, like most consumer goods in our culture, "everything is going to go through its sexy phase." She pointed out that, in her experience, the sexualized images of women were not harmful and that women should be able to use their bodies and their sexuality as they see fit. For Watermelon, the sexual imagery she produced worked in her favour to give her a platform to discuss issues that were important to her and functioned as a source of empowerment. Conversely, Jamie Shaw, who is a past President of the Canadian Association of Medical Cannabis Dispensaries, was critical of the use of sexualized imagery to sell cannabis products and saw it as a product of social conditioning that has taught us to accept the objectification of women in our male dominated consumer capitalist culture.

Most of my participants were unanimous in their assertion that the Boobs and Bongs images that were characteristic of the cannabis industry, though still existent, have been shifting to incorporate a wider variety of female representations in cannabis media. Brandi Woods, the general manager of the Victoria Cannabis Buyers Club expressed that nowadays, "you're starting to see on front covers of magazines like women wearing, you know, their suits they wanna wear or their t-shirts they wanna wear, you know clothing that they want to wear, not this bikini and butts." I would argue that this generalized shift from Boobs and Bongs imagery to women industry leaders in power suits on the cover of High Times is intricately tied to the corporatization of the cannabis industry. As the industry is setting itself up more and more as a legitimate enterprise that consists of business professionals, the representation of women has shifted simultaneously from an over representation of images of women "deep-throating bongs," in the words of Brandi Woods, to a more diverse representation of images of and articles about women in their workplaces, wearing lab coats or tailored suits. This shift can be seen as, at once, a celebration of women's entrepreneurship and as a method by which the industry is working to establish itself as a respectable, legitimate, and professional new field deserving of legalization and incorporation into the free market.

\section{Women against Women}

When I asked my participants about what kind of obstacles they had experienced during their careers in the cannabis industry, they all highlighted resistance primarily from other women. Jamie Shaw, for example, talked about the beginnings of Women Grow in Vancouver and indicated that organizers had a very hard time getting older, more established women industry members to come out and participate in their initiative. Watermelon talked about the shaming she endured from other women after she became a High Times centerfold.

All my participants identified prohibition, and the fear, isolation, and necessary survival strategies created by it, as significant factors in creating barriers to meaningful industry participation and in contributing to such woman against woman aggression. Each of their careers developed in the 
context of federal prohibition and the very real threats and consequences of criminalization. As Shaw pointed out, "when you persecute a group of people, yes that group will get divided." Sarah Campbell, the co-founder and director of the Craft Cannabis Association, described the consequences as follows: "I would say in the past I didn't really meet that many women who were involved in the industry. There wasn't a lot of openness and sharing and you know there was fear and there were more major consequences than there are now."

The legalization of the cannabis industry will be a great advancement in dismantling the culture of fear that has defined women's industry involvement for decades. However, legalization alone will not be enough to foster environments for women to succeed in the legitimate cannabis industry. Programs and legislation that are attuned to the reality of women's economic disadvantages, the history of male domination of cannabis, as well as taking seriously the realities of women's needs and differences will be necessary to create an industry that does not reproduce gender inequalities in this newly legal market.

\section{Gender Essentialism and the Legitimization of the Cannabis Industry}

As a young woman who is deeply invested and involved in the cannabis community, I believe that women will play increasingly significant roles in shaping the industry for the better. I predict women will contribute to moving the cannabis industry away from the male-dominated corporate model toward a more diverse and socially conscious business approach. All of my participants agreed with this perspective, and, in the process, we are all in part reinvesting in biological determinism and the essentialization of femininity that says women will do business differently simply because we are women. Seeing women as essentially different from men reinforces a naturalized binary between men and women that feminist scholars have worked to dismantle for decades. The question at hand is, How does this gender essentialism operate in constructing women's roles in the cannabis industry, and how does it relate to the intersections of racialization, corporatization, and heteronormativity and processes related to legitimizing the industry?

\section{Woman as Healer}

When I asked my participants about the gendered dimensions of the industry and what role they saw women playing, many participants discussed the natural compassion and care that women bring to the industry by drawing on a gender essentialist discourse. Brandi Woods said that the women who work at the Victoria Cannabis Buyers Club are more likely to go out of their way to give a patient a hug when they needed it as opposed to their male budtenders. Woods suggested that women's natural capacities as caring service providers make them more compassionate industry members. Brandi Woods and Jamie Shaw additionally spoke to the ways in which people are often more comfortable talking about their health care needs with a woman than with a man. I refer to this pattern as the Woman as Healer discourse which positions women as naturally compassionate healers and caregivers by virtue of their sex and gender identity, a discourse situated within a binarized and essentialist understanding of gender.

When I began this research, it was my intention to explore what barriers prevented women from taking on leadership roles in the cannabis industry, such as owning dispensaries or being business executives of LPs. In my own experience, I have never met a woman who owns a major cannabis business outside of secondary value-added products such as edibles, topicals, or tinctures. In the process of reviewing my interview data and developing my findings, my research focus shifted because I uncovered gendered norms, binaries, and expectations such as the Woman as Healer discourse that have an influence over the forms of work women do in the cannabis sector. Sarah Campbell, 
co-founder and director of the Craft Cannabis Association, agreed that there is a significant gendered division of labour, in that nearly three-quarters of the value added product side of the cannabis industry is dominated by women. I argue that owning a cannabis bakery or making cannabis lotions (as opposed to operating grow-ops and dispensaries) aligns well with women's assigned roles in the kitchen, preparing food and medicines for families, and the Woman as Healer discourse. Conversely, Watermelon, Brandi, and Sarah described men as the dealers in the industry who are primarily concerned with short-term profits and who have little compassion for patients in the long term. Hence, when Jazmin Hupp, the co-founder of Women Grow, argued that the cannabis industry is a blue skies market for women, she was in part drawing on the assumption that because women are naturally or inherently different from men, they will naturally take a different approach that is more compassionate and inclusive, without interrogating the gendered assumptions and binaries behind that statement. I argue that discussing men's and women's roles in the industry via this biologically deterministic discourse limits men's and women's capacity to operate outside this rigid gender binary. As Ashley Abraham eloquently stated, the cannabis industry is "a brand new legitimate industry, but it's not a brand new industry," and hence it is important to unpack the historic and cultural norms that are operating in order to dismantle the gendered discourses that relegate men and women to predetermined roles.

\section{The Martha Stewart of Weed}

As discussed above, the ongoing prohibition of the cannabis industry has been the biggest factor in shaping the social dimensions of the industry as it exists today. For decades, the cannabis industry existed underground as a black market developed in response to the "War on Drugs." As a result, the cannabis community was largely composed of those living on the social fringes, and cannabis continues to be associated with Stoner Bros living in their mothers' basements or with criminalized gangs. Medicinal cannabis activists have done much to challenge these stereotypes and to sanitize the industry by presenting cannabis as a viable, legitimate, alternative medicine for patients in need. Along with the medical model, women have taken the next step in challenging the Stoner Bro and criminal stereotypes by drawing on the legitimizing power of white, middle-class femininity to normalize the cannabis industry.

For decades, cannabis was associated primarily with men and male criminals and the "War on Drugs" disproportionately criminalized people of color and Indigenous communities attempting to make a living by selling cannabis (Bender, 2016; Boyd, 2015). Seeing a man arrested for cannabis, or people of colour in handcuffs, was and still is a regular occurrence on North American television

news broadcasts (Bjornstrom, Kaufman, Peterson, \& Slater, 2010). Cultural stigma associated with cannabis consumption prevented most members of mainstream society from using cannabis, and prohibition effectively deterred many women from engaging in the cannabis community at all. Sarah Campbell emphasized that if women did participate, it was often done in secret and isolation for fear of the social repercussions or criminalization.

Unlike their male or racialized counterparts, women, and specifically white women, do not fit the visual image of the stoner stereotype or the racialized criminal gang image of the presumed cannabis dealer, a privilege that is not afforded to communities of colour or Indigenous persons as we have seen (Dell \& Kilty, 2013). During our interview, Watermelon described the ways in which she consciously used her white femininity to her advantage when it came to her illegal involvement in the cannabis industry. She described herself and the all-female staff at her cannabis bakery as presenting a "Disney mom" look that embodies a very traditional feminine representation by wearing lots of dresses and aprons. She portrayed this aesthetic as "looking like somebody you wanted to buy and eat food from"; in other words, her feminine image worked in her favour to present herself and 
her staff as respectable and clean providers of cannabis to mainstream consumers. Watermelon also shared that her Disney mom look worked to her advantage when she was involved in three separate provincial trials for distributing marijuana edibles in Vancouver. She explained that when she was arrested for selling pot cookies on Wreck Beach, there was a lot of public outcry because she did not look like a Stoner Bro at all. She was a young, beautiful, blonde woman, and when her image was splashed across television screens throughout Canada, it sparked debates about the lawfulness of marijuana prohibition. Watermelon acknowledged that "if I was a guy that would have been a very different situation." I would further the argument by suggesting that if Watermelon was a woman of colour, it would have also been a very different situation (Boyd, 2015; Dell \& Kilty, 2013).

Watermelon very consciously used her privileged position as an able-bodied, young, beautiful, white woman to overcome the stigmatization of cannabis users. She also indicated that she often "actually manipulate[d] the situation because I'm a woman." Sarah Campbell similarly acknowledged that because she did not look like the Stoner Bro stereotype, she felt inclined to be more open with her cannabis use to challenge the stigma and assumptions of her peers about cannabis consumption.

During our interview, Watermelon described her work in the cannabis edible business and her online cannabis baking show as producing an image of the "Martha Stewart of weed." Martha Stewart, of course, represents the epitome of normative white suburban consumer culture. To be the Martha Stewart of weed is to be the charming woman in an apron, baking homemade goods with cannabis butter for her family. To be the Martha Stewart of weed is to invoke the power of normative white femininity in order to bring cannabis into Canadian homes as a non-threatening leafy green vegetable just like spinach or broccoli. By drawing on these racialized, classed, and gendered images, Watermelon and others like her are drawing on the legitimizing power of white middle-class femininity to make cannabis consumption a part of everyday life, just like Sunday dinner.

Here I make the argument that only a very narrow selection of women who occupy privileged identities are able to draw on the power of biological essentialist binaries because these binaries intersect with privileged race and class identities. For example, Watermelon is able to draw on her Disney mom aesthetic and to mobilize the power of the suburban white mom figure because she herself is a beautiful, young, white, cisgendered woman. In light of Dell and Kilty's work that demonstrates how Aboriginal women are stereotyped as an "expected offender," I argue that women of colour and Aboriginal women cannot draw on the power of the Disney mom image like Watermelon and Sarah Campbell because their racialized identities position them outside of that power dynamic, regardless of how clever or resourceful they are. Therefore, I argue that because only a narrow set of women are able to draw on the power of gender essentialism and biological determinism to gain power and access in the cannabis community, they are indirectly reinforcing the privilege and power dynamics that white upper middle class women hold over marginalized women.

In summary, if beautiful, white, mom-like women are buying cannabis to use in their brownies or if a caregiver is using a cannabis salve to ease the pains of their aging parents, an increasingly white-dominated corporatized industry is setting itself up to sell cannabis to these consumers in well-lit retail dispensaries. While these strategies have allowed cannabis to become accessible to those in need who would otherwise be afraid or suspicious of this medicine, it is still important to emphasize the ways in which privileged identities are being positioned to dissociate cannabis from its roots in resistance, the underground, and in communities of colour in order to present cannabis as a legitimate industry owned and operated by privileged and valued members of society: white, middle-class, heteronormative men and women. 


\section{Conclusion}

My interviews with several prominent women leaders in the cannabis industry in Vancouver and Victoria provided insights into its gendered, racialized, and classed dimensions. These included the racialization and corporatization of the cannabis industry, the sexualized representation of women in cannabis, internal divisions between women industry members, the Woman as Healer discourse, the motivations behind the Martha Stewart of weed, and the roll of heteronormative femininity in legitimizing the cannabis industry.

It is important to ask, Do these representations of women in the cannabis industry, which are in part the product of its corporatization, limit women's access and involvement? Or do these trends simply represent what it means to have women involved? If so, do these trends indicate a re-investment in social structures that activists are working to dismantle elsewhere, such as decolonization, dismantling white corporate culture, denaturalizing gender binaries, or overcoming structural racism? The reason for asking these questions is to interrogate what this "blue skies market" really entails and who is set up to take advantage of it.

The cannabis industry will be one of the most influential industries Canada has ever seen. It is projected to be a multi-billion dollar industry that will have a monumental influence on the national economy, health care, the job market, and much more. As a passionate feminist scholar and an outspoken cannabis activist, I dream of seeing women leading the charge in this ever-expanding cannabis industry. A past manager of mine once said, "we are the pioneers of this industry," and it is the actions women choose today that will set the precedent for how this industry will take form in the future. It is our responsibility to ensure that the cannabis industry does in fact represent a "blue skies" market and that women from all backgrounds do have a voice that is heard and have a seat at the negotiating table when it comes to shaping this multi-billion dollar cannabis industry for the collective good. Before this can happen, however, we must not dismiss the racialized, classed, and gendered histories and social structures in which the cannabis industry was and continues to be embedded. 


\section{References}

Baca, R. [The Cannabist]. (2016, January 6). How are women and minorities fairing in legal marijuana? [Video file]. Retrieved from https://www.youtube.com/watch?v=wg4yFxA1QSY\&index $=3 \&$ list $=$ PLEIanICRbplISfO6GpCh77sxkh3bQWSp

Bender, S. W. (2016). The colors of cannabis: Race and marijuana. U.C. Davis Law Review, $50(2)$, 689.

Bjornstrom, E. E. S., Kaufman, R. L., Peterson, R. D., \& Slater, M. D. (2010). Race and ethnic representation of lawbreakers and victims in crime news: A national study of television coverage. Social Problems, 57(2), 269-293.

Boyd, S. C., 1953. (2015). From witches to crack moms: Women, drug law, and policy (2nd ed.). Durham, NC: Carolina Academic Press.

Crenshaw, K. (1991). Mapping the margins: Intersectionality, identity politics, and violence against women of color. Stanford Law Review, 43(6), 1241-1299. doi:10.2307/1229039

Dawson, C., \& Henley, A. (2015). Gender, risk, and venture creation intentions. Journal of Small Business Management, 53(2), 501-515.

Dell, C. A., \& Kilty, J. M. (2013). The creation of the expected Aboriginal woman drug offender in Canada: Exploring relations between victimization, punishment, and cultural identity.International Review of Victimology, 19(1), 51-68.

Denton, B., \& O'Malley, P. (1999). Gender, trust, and business: Women drug dealers in the illicit economy. The British Journal of Criminology, 39(4), 513-530.

DeVault, M., \& Gross, G. (2006). Feminist interviewing: Experience, talk, and knowledge (S. N. Hesse-Biber, Ed.). In Handbook of feminist research: Theory and praxis (2nd ed., pp. 173-198). Thousand Oaks, CA: Sage.

Frankenberg, R. (1993). White women, race matters: The social construction of whiteness. Minneapolis, MN: University of Minnesota Press.

Gordon, T. (2006). Neoliberalism, racism, and the war on drugs in Canada. Social Justice, 33(1 (103)), 59-78. Retrieved from http://www.jstor.org.ezproxy.library.uvic.ca/stable/29768352

Health Canada (2016). Government of Canada, Healthy Environments and Consumer Safety Branch, Drug Strategy and Controlled Substances Programme. Information on the new Access to Cannabis for Medical Purposes Regulations. Retrieved from http://www.hc-sc.gc.ca/dhpmps/marihuana/about-apropos-eng.php.

Kind, M. [Canna Insider]. (2015, April 19 day). Cultivating Women Leaders in Cannabis with Jazmin Hupp of Women Grow. [Video file]. Retrieved from https://www.youtube.com/watch?v=tW85Kgmps40\&list=PLEIanICRbplISfO6GpCh77sxkh3bQWSp\&index=2.

Lal, J. (1996). Situation locations: The politics of self, identity, "other" in living and writing the text. In D. L. Wolf (Ed.), Feminist dilemmas in fieldwork (pp. 185-214). Boulder, CO: Westview Press.

MacDougall, A., Valley, J., Adler, J., Bettel, C., Param, A., Schmidt, J., Sigurdson, A., Strachan, T., \& Suppa, O. (2017, September 18). 2017 Diversity Disclosure Practices. Retrieved from Osler, Hoskin \& Harcourt LLP website: https://www.osler.com/en/resources/governance/2017/2017. diversity-disclosure-practices-report-women.

Murphy, E. F. 1., Anthony, B., \& Solomon, R. (1973). The black candle. Toronto, ON: Coles Pub. Co.

Pila, D. (2014). Racism. In C. Forsyth \& H. Copes (Eds.), Encyclopedia of social deviance (pp. 579-581). Thousand Oaks, CA: Sage.

Schwartz, D. (2014, May 06). A Canadian mystery: Why was pot criminalized in 1923? Retrieved from http://www.cbc.ca/news/health/marijuana-was-criminalized-in-1923-but-why1.2630436 
The Arbutus Review • 2018 • Vol. 9, No. 1 • https://doi.org/10.18357/tar91201818385

Scotti, M. (2018, June 20) Marijuana to be legal in Canada starting October 17, Trudeau confirms. Global News. Retrieved from https://globalnews.ca/news/4285946/marijuana-legal-dateoctober-17-canada-trudeau-confirms. 